\title{
Respon Pertumbuhan dan Produksi Tomat (Solanum lycopersicum) pada Berbagai Jenis Penggunaan Mulsa dan Frekuensi Penyiraman
}

\section{Response to Tomato Growth and Production (Solanum lycopersicum) on Different Types of Mulch Use and Watering Frequency}

\author{
Zul Aida Mangesti ${ }^{1 *}$, Susilo Budiyanto ${ }^{2}$, Sutarno ${ }^{2}$ \\ ${ }^{1}$ Program Studi Agroteknologi, Departemen Pertanian, Fakultas Peternakan dan Pertanian \\ Universitas Diponegoro \\ ${ }^{2}$ Departemen Pertanian, Fakultas Peternakan dan Pertanian, Universitas Diponegoro \\ *Email : ristyslvn@gmail.com \\ *Email: zulaidamangesti07@gmail.com
}

Diterima 29 Juli 2019 / Disetujui 6 Agustus 2019

\begin{abstract}
ABSTRAK
Gunung pati merupakan daerah di kota semarang yang mempunyai curah hujan tertinggi (2400-2600 $\mathrm{mm} / \mathrm{tahun}$ ). Namun, hari hujan sedikit sehingga berpengaruh terhadap ketersediaan air di dalam tanah yang berakibat pada kondisi suhu dan kelembaban tanah. Tujuan dari penelitian untuk mengetahui jenis mulsa serta frekuensi penyiraman yang paling sesuai untuk pertumbuhan dan produksi tomat. Penelitian ini menggunakan Rancangan Acak Lengkap (RAL) pola faktorial 4 × 2 sebanyak 3 ulangan. Faktor Pertama terdiri dari penggunaan jenis mulsa dengan 4 jenis perlakuan,yaitu $\mathrm{M}_{0}$ : tanpa mulsa, $\mathrm{M}_{1}$ : mulsa jerami, $\mathrm{M}_{2}$ : mulsa perak, $\mathrm{M}_{3}$ : mulsa hitam. Faktor kedua terdiri dari frekuensi penyiraman dengan 2 taraf perlakuan, yaitu $\mathrm{P}_{1}$ : 1 hari sekali dan $\mathrm{P}_{2}$ : penyiraman 2 hari sekali. Variabel yang diamati adalah komponen pertumbuhan yang terdiri dari tinggi tanaman, jumlah daun serta produksi tanaman tomat yang terdiri dari jumlah buah, bobot buah, serta kadar air buah. Data yang diperoleh kemudian dianalisis ragam dan dilanjutkan dengan uji Duncan's Multiple Range Test (DMRT). Berdasarkan hasil penelitian dapat disimpulkan bahwa penggunaan mulsa perak frekuensi penyiraman 1 hari sekali mampu memberikan rata- rata suhu tanah terendah yaitu $29^{\circ} \mathrm{c}$, memberikan rata-rata kelembaban tanah tertinggi yaitu $41,7 \%$ serta dapat memberikan hasil tertinggi pada pertumbuhan tinggi tanaman rata-rata setinggi $107,2 \mathrm{~cm}$ dan pada produksi tanaman memberikan rata- rata bobot buah terbesar yaitu $37,2 \mathrm{gr}$.
\end{abstract}

Kata kunci : air, suhu tanah, kelembaban tanah

\begin{abstract}
Gunung pati is an area in Semarang which has the highest rainfall (2400-2600 mm / year). But, the rainy days are small so affect the availability of water in the soil which results in conditions of soil temperature and humidity. The purpose of the study was to find out the mulch and the frequency of watering that was most suitable for tomato growth and production. This research used Rancangan Acak Lengkap (RAL) factorial $4 \mathrm{x}$ 2, 3 replications. The first factor consisted of the use of mulch types with 4 types of treatment, namely M0: without mulch, M0: Without mulch, M1: rice straw mulch and M2: silver plastic mulch, M3: black plastic mulchThe second factor consists of frequency of watering with 2 levels of treatment, namely P1: once a day and P2: once every two days. The variables observed were growth components consisting of plant height, number of leaves and tomato plant production consisting of the number of fruits, weight of fruit and fruit moisture content. The data obtained were then analyzed for variance and continued with Duncan's Multiple Range Test. Based on the results of the study it can be concluded that the use of silver mulch once watering frequency is able to provide the lowest average soil temperature of $29 \mathrm{oc}$, giving the highest average soil moisture, which is $41.7 \%$ and can provide the highest yield on the average plant height growth $107.2 \mathrm{~cm}$ and in plant production it gives the largest fruit weight average of $37.2 \mathrm{gr}$.
\end{abstract}

Keywords : water, soil temperature, soil moisture 


\section{PENDAHULUAN}

Tomat merupakan sayuran yang banyak dibudidayakan di dunia. Tomat merupakan sumber vitamin A dan C. Vitamin A (karoten) yang terdapat pada tomat dapat membantu penyembuhan penyakit buta malam (Anggorowati, 2016). Tahun 2014 produksi tomat sebesar 915.987 ton dan pada tahun 2015 produksi tomat mengalami penurunan menjadi 877.792 ton (Sektetariat Dirjen Hortikultura, 2016). Untuk memenuhi permintaan tomat yang terus meningkat, maka perlu dilakukan peningkatan produksi tomat. Kendala yang sering dihadapi dalam memenuhi kebutuhan pasar dan ekspor tomat terletak pada ketidaksesuaian antara yang dibutuhkan pasar dengan produk yang dihasilkan. Budidaya tomat mempunyai resiko kegagalan dan biaya yang cukup tinggi. Kemampuan tomat untuk dapat menghasilkan buah sangat tergantung pada interaksi antara pertumbuhan tanaman dan kondisi lingkungannya (Pangaribuan dkk, 2011). Salah satu faktor yang mempengaruhi pertumbuhan tanaman tomat adalah ketersediaan air. Air merupakan faktor pembatas bagi tanaman tomat (Indrawati, 2012). Kelebihan atau kekurangan air akan mengakibatkan produksi dan kualitas dari tanaman tomat menurun. Akar pada tanaman tomat membutuhkan oksigen tinggi, sehingga akar tanaman tomat tidak boleh tergenang. Tomat sangat rentan terhadap taraf dan frekuensi air, karena dapat mempengaruhi kualitas sifat-sifat fisik buah yang dihasilkan. Pertumbuhan tanaman tomat akan menjadi baik jika ditanam di tanah yang memiliki tata air baik (Wijayanti, 2013). Pemberian air derngan kadar yang berbeda akan mempengaruhi pertambahan tinggi batang tanaman tomat. Pemberian air terlalu banyak atau terlalu sedikit akan menghasilkan pertumbuhan tinggi tanaman tomat yang kurang optimum, sedangkan kadar air yang mendekati batas normal akan menghasilkan pertumbuhan tanaman tomat yang optimal dan kadar air yang tepat untuk membudidayakan tanaman tomat adalah $350 \mathrm{ml}$ per hari untuk intensitas penyiraman sekali (Munawaroh, 2014).

Gunung pati merupakan daerah di kota Semarang yang mempunyai curah hujan berkisar antara 2400-2600 mm/tahun. Suhu udara pada musim kemarau berkisar $30^{\circ}-33^{\circ} \mathrm{c}$ (Dewi dan Rudiarto, 2013) dan kelembaban sekitar 65\%. Angka curah hujan yang tinggi, namun hari hujan di daerah tersebut sedikit. Sehingga fluktuasi hujan di daerah tersebut tinggi. Hal tersebut berpengaruh terhadap ketersediaan air yang ada di dalam tanah yang berpengaruh terhadap suhu dan kelembapan tanah. Oleh karena itu diperlukan pengaturan suhu dan kelembapan tanah maka dengan menggunakan mulsa. Penggunaan mulsa untuk menutupi tanah merupakan salah satu cara untuk mengubah iklim tanah atau iklim mikro dekat permukaan tanah (Munawaroh, 2014). Pemanfaatan mulsa untuk menutup tanah akan mempengaruhi iklim tanah yang pengaruhnya dapat dilihat dari suhu, kelembaban, serta terhadap pertumbuhan dan produksi tanaman. Mulsa bahan organik menggunakan jerami, pupuk kandang atau serbuk kayu. Tujuan dari penelitian ini adalah untuk mempelajari dan mengkaji pemgaruh penggunaan berbagai jenis mulsa dan frekuensi penyiraman untuk tanaman tomat serta untuk mengetahui mulsa serta frekuensi penyiraman yang paling sesuai untuk pertumbuhan dan produksi tomat.

\section{METODE PENELITIAN}

Penelitian ini dilaksanakan Juli- Oktober 2018 di Lahan Pertanian Gunungpati, Kelurahan Sekaran dan Laboratorium Ekologi dan Produksi Tanaman Fakultas Peternakan dan Pertanian, Universitas Diponegoro Semarang. Materi yang digunakan dalam penelitian yaitu, benih tomat F1 andhini, pupuk kandang, pupuk organik cair merk SNN dengan kandungan hara mikro $\mathrm{N} 25 \%, \mathrm{P}$ $25 \%$, dan $\mathrm{K} 25 \%$ serta hara mikro besi, natrium, seng, tembaga. Alat yang digunakan dalam penelitian ini yaitu mulsa jerami, mulsa plastik perak, mulsa plastik hitam, hygrometer tanah, thermometer tanah, pelubang mulsa, alat penyiraman, ajir, sprayer, penggaris, timbangan, oven dan alat tulis.

Penelitian menggunakan Rancangan Acak Lengkap (RAL) pola faktorial $4 \times 2$ dengan 3 kali ulangan. Faktor pertama adalah penggunaan berbagai jenis mulsa (M) dengan empat taraf : $M_{0}$ $=$ tanpa mulsa $\mathbf{M}_{1}=$ mulsa jerami, $\mathbf{M}_{2}=$ mulsa 
plastik perak, $\mathrm{M}_{3}=$ mulsa plastik hitam. Faktor kedua adalah perlakuan frekuensi penyiraman yang terdiri dari dua taraf $\mathrm{P}_{1}=$ penyiraman 1 hari sekali, $\mathrm{P}_{2}=$ penyiraman 2 hari sekali. Kombinasi dua fakor penelitian diperoleh 8 perlakuan dengan masing-masing diulang tiga kali sehingga diperoleh 24 unit percobaan.

Prosedur Penelitian penelitian dilakukan dalam beberapa tahapan yaitu tahap persiapan penelitian, perlakuan, pengambilan dan pengolahan data. Tahap persiapan berupa pengolahan tanah di lahan yang akan digunakan untuk penelitian. Tanah dicangkul kemudian dibentuk bedengan sebanyak 24 bedeng dengan luas $3 \times 2,1$ meter dan diberi pupuk kandang sebagai pupuk dasar sebanyak $10 \mathrm{~kg}$ per bedengnya. Persiapan bibit tanaman tomat adalah dengan cara menyemaikan benih tomat di dalam tray selama 4 minggu.Tahap perlakuan yaitu pemberian mulsa dan frekuensi penyiraman yang masing- masing diulang sebanyak 3 kali sehingga keseluruhan terdapat 24 unit percobaan. Penempatan perlakuan penyiraman dan jenis mulsa dilakukan secara acak. Setelah mulsa dipasang sesuai perlakuannya, bibit tomat yang telah disemaikan dipindah ke lahan. Setiap 1 bedeng terdapat 42 tanaman tomat. Pemupukan dilakukan dengan cara penambahan pupuk organik cair (POC). Perawatan tanaman tomat yang dibutuhkan adalah penyiangan yang dilakukan jika ada gulma, pemangkasan tunas yang tumbuh di bagian ketiak daun dilakukan 1 minggu sekali serta pemasangan bambu untuk menopang tanaman tomat ketika tanaman tomat berumur 2 minggu setelah tanam. Tanaman tomat dirawat sampai berumur \pm 60 hari.

Penyemaian benih tomat dilakukan dengan menyiapkan media untuk persemaian benih. Benih yang telah dipersiapkan di rendam semalam dengan tujuan untuk menyeleksi benih yang rusak dan baik, serta untuk mempercepat perkecambahan. Menjaga kelembapan tempat persemaian dengan penyemprotan. Penyemaian bibit dilakukan selama 4 minggu atau benih menjadi bibit siap tanam.

Persiapan lahan dilakukan 2 minggu sebelum pindah tanam dengan cara mencangkul lahan kemudian diukur setiap bedengnya $3 \times 2,1$ meter. Setiap bedeng diberikan pupuk kandang sebagai pupuk dasar sebanyak $10 \mathrm{~kg}$ per bedengnya. Pada saat tanaman akan dipindah, bedeng yang diberiperlakuan mulsa plastik dipasang mulsanya terlebih dahulu, kemudian dilubangi sesuai dengan jarak tanam yang telah ditentukan.

Bibit tomat yang telah berumur 4 minggu atau sudah siap pindah tanam, dipindahkan ke bedengan yang telah disiapkan. Setelah bibit sudah dipindahkan, untuk bedengan yang diberi perlakuan mulsa jerami pada bedengan ditutupi oleh jerami kering setebal $4,5 \mathrm{~cm}$. Pemupukan dilakukan pada saat tanaman berumur 14 HST sampai 28 HST. Pemupukan diberikan setiap 7 hari sekali menggunakan $10 \mathrm{ml}$ pupuk organik cair dilarutkan dalam $100 \mathrm{ml}$ air. Pemupukan dilakukan dengan cara menyemprotkan ke tanaman. Pemanenan tomat dilakukan setelah tanaman berumur 60-80 hari setelah tanam. Pemanenan dilakukan selama 3 kali, selisih antar panen berjarak 5-7 hari.

Pengamatan dan pengumpulan data. Pengamatan dan pengumpulan data dilakukan setiap minggu sekali pada fase vegetatif. Pengamatan dan pengumpulan data yaitu dengan mengukur suhu dan kelembaban, tinggi tanaman $(\mathrm{cm})$, menghitung jumlah daun pada tiap tanaman, menghitung jumlah buah per tanaman, bobot buah per tanaman, menghitung berat basah tanaman dan berat kering tanaman. Data yang diperoleh diolah dengan analis ragam dan dilanjutkan dengan uji Duncan's Multiple Range Test.

\section{HASIL DAN PEMBAHASAN}

\section{Suhu Tanah}

Hasil pengamatan suhu tanah terhadap perlakuan pemberian berbagai jenis mulsa dan frekuensi penyiraman disajikan pada Tabel 1. Tabel 1. Menunjukkan bahwa pada frekuensi penyiraman 1 hari sekali suhu terendah terdapat pada mulsa plastik perak $\left(29^{\circ} \mathrm{C}\right)$ dan mulsa plastik hitam $\left(29^{\circ} \mathrm{c}\right)$. Pada frekuensi penyiraman 2 hari sekali suhu terendah terdapat pada mulsa plastik perak $\left(30^{\circ} \mathrm{c}\right)$ dan mulsa plastik hitam $\left(30^{\circ} \mathrm{c}\right)$. Hal ini menunjukkan bahwa pemberian mulsa perak memberikan suhu tanah lebih rendah karena mulsa 
perak memantulkan cahaya matahari sehingga radiasi matahari yang diterima oleh tanah menjadi lebih sedikitdan hal tersebut menyebabkan suhu tanah lebih rendah. Hal ini sesuai dengan pendapat Kadarso (2008) yang menyatakan penggunaan mulsa perak akan membantu menurunkan suhu tanah, mempertahankan kelembaban tanah serta memperbesar radiasi matahari yang diterima oleh daun sehingga meningkatkan proses fotosintesis. Suhu rerata tanah pada frekuensi penyiraman 1 hari sekali lebih rendah dibandingkan frekuensi penyiraman 2 hari sekali. Frekuensi penyiraman 1 hari sekali mampu memberikan suhu tanah yang lebih rendah dikarenakan pemberian air akan mampu mempertahankan suhu tanah. Hal ini sesuai dengan pendapat Damaiyanti(2013) yang menyatakan kadar air dalam tanah berpengaruh terhadap keadaan lengas tanahserta suhu dan kelembaban tanah. Apabila suhu tanah tinggi, makaevaporasi yang terjadi pada air tanah juga tinggi sehingga kandungan air tanah akan cepat berkurang. Apabila kebutuhan air pada tanaman tomat tidak terpenuhi maka proses fisiologis pada tanaman tomat akan terganggu yang mengakibatkan pertumbuhan dan produksinya akan terhambat.

Tabel 1. Rata-rata Suhu Tanah $\left({ }^{\circ} \mathrm{C}\right)$

\begin{tabular}{cccc}
\hline Perlakuan & P1 & P2 & Rata- Rata Suhu Tanah \\
\hline $\mathbf{M}_{\mathbf{0}}$ & $30.6^{\mathrm{a}}$ & $30.6^{\mathrm{a}}$ & $30.6^{\mathrm{a}}$ \\
$\mathbf{M}_{\mathbf{1}}$ & $31.0^{\mathrm{a}}$ & $31.0^{\mathrm{a}}$ & $31.0^{\mathrm{a}}$ \\
$\mathbf{M}_{\mathbf{2}}$ & $29.0^{\mathrm{c}}$ & $30.0^{\mathrm{b}}$ & $29.0^{\mathrm{b}}$ \\
$\mathbf{M}_{\mathbf{3}}$ & $29.0^{\mathrm{c}}$ & $30.0^{\mathrm{b}}$ & $29.5^{\mathrm{b}}$ \\
\hline
\end{tabular}

Rata- Rata Suhu Tanah

$29.9^{\mathrm{b}}$

$30.4^{\mathrm{a}}$

Keterangan: Superskrip berbeda pada baris yang sama menunjukkan perbedaan yang nyata $(\mathrm{P}<0,05) . \mathrm{M}_{0}=$ Tanpa Mulsa, $\mathrm{M}_{1}=$ Mulsa Jerami, $\mathrm{M}_{2}=$ Mulsa Perak, $\mathrm{M}_{3}=$ Mulsa Hitam, $\mathrm{P}_{1}=1$ hari sekali, $\mathrm{P}_{2}=2$ hari sekali

\section{Kelembaban Tanah}

Tabel 2. Rata-rata Kelembaban Tanah (\%)

\begin{tabular}{cccc}
\hline Perlakuan & P1 & P2 & Rata- Rata Kelembaban Tanah \\
\hline M0 & $31.1^{\mathrm{d}}$ & $28.9^{\mathrm{d}}$ & $30.0^{\mathrm{c}}$ \\
M1 & $16.7^{\mathrm{f}}$ & $20.0^{\mathrm{e}}$ & $18.3^{\mathrm{d}}$ \\
M2 & $46.6^{\mathrm{a}}$ & $36.6^{\mathrm{c}}$ & $41.7^{\mathrm{a}}$ \\
M3 & $43.3^{\mathrm{b}}$ & $30.0^{\mathrm{d}}$ & $36.6^{\mathrm{b}}$ \\
\hline
\end{tabular}

Rata- Rata KelembaanTanah $\quad 34.5^{\mathrm{a}} \quad 28.89^{\mathrm{b}}$
rangan: Superskrip berbeda pada baris yang sama menunjukkan perbedaan yang nyata $(\mathrm{P}<0,05) . \mathrm{M}_{0}=$ Tanpa Mulsa, $\mathrm{M}_{1}=$ Mulsa Jerami, $\mathrm{M}_{2}=$ Mulsa Perak, $\mathrm{M}_{3}=$ Mulsa Hitam, $\mathrm{P}_{1}=1$ hari sekali, $\mathrm{P}_{2}=2$ hari sekali.

Tabel 2. Menunjukkan bahwa pada frekuensi penyiraman 1 hari sekalikelembaban tertinggi terdapat pada perlakuan jenis mulsa plastik perak $(46,6 \%)$. Pada frekuensi penyiraman 2 hari sekali kelembaban tertinggi terdapat pada perlakuan jenis mulsa plastik perak $(36,6 \%)$. Hal ini menunjukkan bahwa Pemberian mulsa perak memberikan kelembaban tanah lebih tinggi karena mulsa perak memantulkan cahaya matahari sehingga mengurangi panas yang diterima oleh tanah hal tersebutsesuai pendapat Haryomo (2009) yang menyatakan mulsa plastik perak menyebabkan panas yang mengalir ke dalam tanah lebih sedikit dibanding tanpa mulsa sehingga tanah yang diberi mulsa akan menmberikan kelembaban yang lebih tinggi dibanding tanpa mulsa. Apabila panas dari matahari yang diterima oleh tanah banyak maka akan terjadi evaporasi yang tinggi. evaporasi yang tinggi menyebabkan kelembaban tanah di sekitar tanaman tomat rendah. Hal ini akan mempengaruhi kandungan air yang ada di dalam tanah sehingga tanaman akan sulit 
menyerap air melalui akar tanaman. Air yang akan diedarkan ke seluruh bagian tanaman tomat tidak mencukupi kebutuhan tanaman tomat sehingga pertumbuham dan produksinya akan terhambat.

\section{Tinggi Tanaman}

Hasil pengamatan tinggi tanaman terhadap perlakuan pemberian berbagai jenis mulsa dan frekuensi penyiraman disajikan pada Tabel 3 . Tabel 3. Menunjukkan bahwa pada frekuensi penyiraman 1 hari sekali tinggi tanaman tertinggi terdapat pada perlakuan mulsa jerami $(106,9 \mathrm{~cm})$. Pada frekuensi penyiraman 2 hari sekali tinggi tanaman tertinggi terdapat pada perlakuan mulsa plastik perak $(125,1 \mathrm{~cm})$. Hal ini menunjukkan bahwa rerata tinggi tanaman pada perlakuan mulsa plastik perak menunjukan rerata tinggi tanaman lebih tinggi dibandingkan dengan perlakuan mulsa lain. Hal ini menunjukan bahwa pada perlakuan tersebut tercapai kondisi tanah yang baik untuk pertumbuhan tinggi tanaman. Air yang tersedia pada kondisi tersebut mencukupi kebutuhan air pada tomat sehingga pertumbuhannya optimal. Wiryanta dan Benardinus (2012) menyatakan bahwa tanaman famili Solanaceae sangat rentan terhadap kekurangan dan kelebihan air selama masa pertumbuhan, pemberian air dan frekuensi pemberian air yang sesuai terhadap tanaman tomat agar dapat mempercepat pertumbuhan. Jumlah air yang sesuai mempercepat pertumbuhan sampai pembentukan ukuran buah. Bila jumlah air yang diberikan semakin banyak, kelebihan air menjadi tidak bermanfaat atau tidak efisien.

Tabel 3. Rata-rata Tinggi Tanaman (cm)

\begin{tabular}{cccc}
\hline Perlakuan & P1 & P2 & Rata- Rata TinggiTanaman \\
\hline M0 & $84^{\mathrm{d}}$ & $46.9^{\mathrm{f}}$ & $65.4^{\mathrm{c}}$ \\
M1 & $106.9^{\mathrm{b}}$ & $72.2^{\mathrm{e}}$ & $89.5^{\mathrm{b}}$ \\
M2 & $89.5^{\mathrm{c}}$ & $125.1^{\mathrm{a}}$ & $107.2^{\mathrm{a}}$ \\
M3 & $84.6^{\mathrm{d}}$ & $49.3^{\mathrm{f}}$ & $66.9^{\mathrm{c}}$ \\
\hline
\end{tabular}

Rata- Rata Tinggi Tanaman

$91.25^{\mathrm{a}} \quad 73.36^{\mathrm{b}}$

Keterangan: Superskrip berbeda pada baris yang sama menunjukkan perbedaan yang nyata $(\mathrm{P}<0,05) . \mathrm{M} 0=$ Tanpa Mulsa, M1= Mulsa Jerami, M2= Mulsa Perak, M3= Mulsa Hitam, P1= 1 hari sekali, P2= 2 hari sekali.

\section{Jumlah Daun}

Tabel 4. Rata-rata Jumlah Daun Tanaman Tomat

\begin{tabular}{cccc}
\hline Perlakuan & P1 & P2 & Rata- Rata Jumlah Daun \\
\hline M0 & $47.2^{\mathrm{b}}$ & $14.33^{\mathrm{f}}$ & $30.9^{\mathrm{b}}$ \\
M1 & $83.2^{\mathrm{a}}$ & $17.13^{\mathrm{e}}$ & $50.1^{\mathrm{a}}$ \\
M2 & $34.4^{\mathrm{c}}$ & $31.6^{\mathrm{c}}$ & $33.0^{\mathrm{b}}$ \\
M3 & $26.6^{\mathrm{d}}$ & $25.13^{\mathrm{d}}$ & $25.8^{\mathrm{c}}$ \\
\hline Rata- Rata Jumlah Daun & $47.8^{\mathrm{a}}$ & $22.14^{\mathrm{b}}$ &
\end{tabular}

\footnotetext{
Keterangan: Superskrip berbeda pada baris yang sama menunjukkan perbedaan yang nyata $(\mathrm{P}<0,05) . \mathrm{M} 0=$ Tanpa Mulsa, M1= Mulsa Jerami, M2= Mulsa Perak, M3= Mulsa Hitam, P1= 1 hari sekali, P2= 2 hari sekali.
}

Tabel 4. Menunjukkan pada frekuensi penyiraman 1 hari sekali jumlah daun tertinggi terdapat pada perlakuan mulsa jerami (83,2 helai), pada frekuensi penyiraman 2 hari sekali jumlah daun tertinggi terdapat pada perlakuan mulsa perak sebesar (31,6 helai). Jumlah daun pada perlakuan mulsa jerami dengan frekuensi penyiraman 1 hari sekali memberikan hasil paling tinggi dibandingkan dengan perlakuan mulsa jenis lain. Jumlah daun pada mulsa jerami dengan frekuensi penyiraman 1 kali paling tinggi karena mulsa jerami mampu memberikan iklim mikro yang 
mendukung aktivitas mikroorganisme dalam tanah dan mampu meningkatkan unsur hara sehingga berpengaruh terhadap jumlah daun tanaman tomat. Damaiyanti dkk (2013) menyatakan bahwa mulsa jerami mampu mengurangi pertumbuhan gulma dan dapat menjaga kestabilan kelembaban dalam tanah sehingga mikroorganisme aktif dalam mendekomposisi bahan organik yang dibutuhkan tanaman pada pertumbuhan organ vegetatif tanaman.

\section{Bobot BuahTomat}

Tabel 5. Rata-rata Bobot Buah (gr)

\begin{tabular}{cccc}
\hline Perlakuan & P1 & P2 & Rata- Rata Bobot Buah \\
\hline M0 & $30.1^{\mathrm{c}}$ & $11.5^{\mathrm{f}}$ & $20.8^{\mathrm{d}}$ \\
M1 & $36.7^{\mathrm{b}}$ & $18.4^{\mathrm{e}}$ & $27.5^{\mathrm{b}}$ \\
M2 & $43.7^{\mathrm{a}}$ & $31.6^{\mathrm{c}}$ & $37.6^{\mathrm{a}}$ \\
M3 & $37.8^{\mathrm{b}}$ & $25.8^{\mathrm{d}}$ & $21.8^{\mathrm{c}}$ \\
\hline Rata- Rata Bobot Buah & $37.1^{\mathrm{a}}$ & $21.8^{\mathrm{b}}$ &
\end{tabular}

\footnotetext{
Keterangan: Superskrip berbeda pada baris yang sama menunjukkan perbedaan yang nyata $(\mathrm{P}<0,05) . \mathrm{M} 0=$ Tanpa Mulsa, M1= Mulsa Jerami, M2= Mulsa Perak, M3= Mulsa Hitam, P1= 1 hari sekali, P2= 2 hari sekali.
}

Tabel 5. Menunjukkan bahwa pada frekuensi penyiraman 1 hari sekali bobot buah tertinggi terdapat pada perlakuan mulsa plastik perak(43,7 g). Pada frekuensi penyiraman 2 hari sekali bobot buah tertinggi terdapat pada perlakuan mulsa plastik (31,6 g). Hal ini menunjukkan kondisi suhu dan kelembaban tanah pada perlakuan tersebut paling optimal dalam meningkatkan produksi tanaman tomat (bobot buah). Hal ini sesuai dengan pendapat Kusuma dkk (2015) yang menyatakan menyatakan jumlah air optimal mempercepat pertumbuhan sampai pembentukan ukuran buah. Mulsa plastik perak memiliki kelebihan mampu memantulkan sinar matahari agar terkena daun sehingga proses fotosintesis menjadi optimal sehingga tanaman tomat akan dapat memproduksi buah secara optimal. Ketersediaan air tanah cukup untuk memenuhi kebutuhan tanaman tomat karena mulsa plastik perak dapat menjaga suhu dan kelembaban tanah yang berpengaruh terhadap ketersediaan air yang ada di dalam tanah agar tidak cepat menguap. Hal ini sesuai dengan pendapat Kadarso (2008) yang menyatakan permukaan perak pada mulsa dimaksudkan agar pemantulan radiasi sinar matahari memiliki efek ganda, yaitu memperkecil panas yang mengalir ke tanah dan memperbesar radiasi matahari yang diterima oleh daun sehingga meningkatkan proses fotosintesis.

\section{KESIMPULAN}

Berdasarkan hasil penelitian dapat disimpulkan bahwa penggunaan mulsa perak frekuensi penyiraman 1 hari sekali mampu menurunkan suhu tanah, meningkatkan kelembaban tanah serta dapat memberikan hasil tertinggi pada pertumbuhan dan produksi tanaman.

\section{DAFTAR PUSTAKA}

Abdurachman A., A. Dariah, dan A. Mulyani. 2008. Strategi dan teknologi pengelolaan lahan kering mendukung pengadaan pangan nasional. J. Litbang Pertanian. 27(2):43-49.

Anggorowati, D., Roedy, S., dan Ninuk, H. 2016. Respon tanaman tomat (Lycopersicum esculentum Mill) pada berbagai tingkat ketebalan mulsa jerami padi. J. Prod Tanaman 4(5):378-384.

Ardiyaningsih P. L. 2011. Pengaruh Pupuk Organik Cair terhadap Pertumbuhan dan Hasil Tanaman Tomat (Lycopersicum esculentum Mill..). J. Agron. Indonesia2 (1) : $114-120$

Baharuddin, R., M.A. Chozin, M. danSyukur. 2014. Toleransi 20 genotipe tanaman tomat terhadap naungan. J. Agron. Indonesia 42(2) : 130-135. 
Damaiyanti D. R. R., N. Aini, dan Koesriharti.2 013. Kajian penggunaan macam mulsa organik pada pertumbuhan dan hasil tanaman cabai besar (Capsicum annuum L.). J. Hortikultura. 1 (2) : 25-32.

Dewi, N.K., dan Iwan, R. 2013. Identifikasi alih fungsi lahan pertanian dan kondisi social ekonomi masyarakat daerah pinggiran di Kecamatan Gunung Pati Kota Semarang. $J$. Wilayah dan Lingkungan. 1 (2): 175-188.

Haryono, G. 2009. Mulsa plastik pada budidaya pertanian. J. Agron. Indonesia 31 (1): 60-68.

Kadarso. 2008. Kajian penggunaan jenis mulsa terhadap hasil tanaman cabai merah varietas red charm. J. Agron. Indonesia. 10(2) : 134139.

Kusuma, A. H. dan M. U. Zuhro. 2015. Pengaruh varietas dan ketebalan mulsa jerami padipada pertumbuhan dan hasil tanaman tomat (Lycopersicum esculentum Mill).J. Agron. Indonesia. 2(1): 1-20.

Lestari, Amelia., Hastuti, E.D., Haryanti, S. 2018. Pengaruh kombinasi pupuk NPK dan pengapuran pada tanah gambut rawa pening terhadap pertumbuhan tanaman tomat (Lycopersicum esculentum Mill.). B. Anatomi dan Fisiologi. 3 (1): 1-10.

Munawaroh, F. 2014. Respon produksi tanaman tomat varietas tora terhadap perbedaan kondisi iklim mikro akibat pemakaian mulsa perak dan hitam. Institut Pertanian Bogor, Bogor. (Skripsi).

Nurhayati. 2009. Pengaruh cekaman air pada dua jenis tanah terhadap pertumbuhan dan hasil kedelai (Glycine max (L.) Merril). J. Floratek. 4(2): 55-64.

Pangaribuan, H.D., Octa, L.P., Lismawanti. 2011. Pengurangan pemakaian pupuk anorganik dengan penambahan bokashi serasah tanaman pada budidaya tanaman tomat. $J$. Agron. Indonesia 39 (3):173- 179.

Sekretariat Dirjen Hortikultura. 2016. Produksi Tanaman Sayuran di Indonesia Periode 2014-2015. Jakarta.
Wasonowati, C. 2011. Meningkatkan pertumbuhan tanaman tomat (Lycopersicum esculentum) dengan sistem budidaya hidroponik. $J$. Agrovivor. 4(1): 21-27.

Wiryanta, W., Bernardinus T. BertanamTomat. 2012. Agromedia Pustaka, Jakarta.

Wulansari, D., Koesriharti., dan Heddy, S. 2017. Pengaruh wiwilan dan aplikasi kombinasi pupuk daun dan $\mathrm{KCl}$ pada pertumbuhan dan hasil tanaman tomat (Lycopersicum esculentum Mill.). J. Prod. Tanaman. 5(10): 1653-1660.

Yulianingrum, H., Edi, S., Prihasto, S.2016. Pengaruh Pemberian Mulsa Jerami Padi terhadap Kelimpahan Gulma dan Pertumbuhan Tanaman Tomat (Solanum lycopersicum) di Lahan Tadah Hujan. J. Agrohorti 2(1) : 2460-2480. 